\title{
Developing the SAPS website for optimal service delivery
}

\author{
NE Sonderling ' and T J D Bothma ${ }^{2}$ \\ Department of Information Science, University of Pretoria \\ communicationresearch@saps.org.za, tbothma@up.ac.za
}

\begin{abstract}
Received: $3^{\text {rd }}$ September 2004
Revised: $22^{\text {nd }}$ October 2004
\end{abstract}

\begin{abstract}
This article discusses a study undertaken to enhance online service delivery by the South African Police Service (SAPS) by means of its website. It makes various recommendations to achieve this, following various investigations. The SAPS describes its primary goal as "service to the public". This is in line with the South African government's Batho Pele ("People first") initiative to improve the delivery of public services. However, as society is changing in response to the demands of the Internet Age, service providers (for the purpose of this study, police agencies) must, too, adjust. The application of e-Governance will enable these agencies to serve the public with a wide variety of information and services. This study makes recommendations in this regard as well. In the initial study for this work user needs regarding the establishment of the SAPS website were assessed. Subsequently a study was conducted to determine best practices in various English-speaking countries, using an evaluation framework compiled for this purpose. Based on the results gained a measuring instrument was designed to evaluate the SAPS website. Four expert evaluators were then requested to do so. The assessment of possible shortcomings of the SAPS website and recommendations for enhancing online service delivery and e-Governance by the study are set out in the article.
\end{abstract}

\section{Introduction}

All police agencies worldwide have a common purpose: To deliver effective service to the communities in which they are situated. Consequently police agency websites also aim for service delivery.

The South African Police Service (SAPS), too, in essence stands for service delivery. This is underlined by the SAPS national strategy (SAPS 2002a: 6), which emphasises the importance of providing service to its clients, namely the members of the South African public. This is in line with its own mission and with government strategy, which is very clear on the purpose of service delivery. It further embodies the Service Delivery Improvement Programme (SDIP) of the SAPS: "The primary goal is service to the public" (SAPS s.a.: 78). Recent research by the Institute for Security Studies (ISS) at 45 of the 219 SAPS priority police stations indicates that most people who dealt directly with the police were satisfied with the services they received. This is in sharp contrast to general public perceptions of the police (ISS 200I).

The SDIP seeks to improve service delivery to communities at local level. The programme provides police station managers with practical tools to improve service delivery while seeking to inculcate a culture of participative management and increased community involvement. In this regard Groenewald (in North 1998:13) emphasises that an approach of ownership in development is important and that people should be empowered to take part in the process.

The SDIP also ties in with the South African government's Batho Pele ("People first") initiative to improve the delivery of public services. Improving service delivery is one of the government's eight priorities as set out in the White Paper on the Transformation of the Public Service (cf. Department of Public Service and Administration 2002).

Service delivery within the SAPS includes determining and meeting the public's information needs that pertain to safety and security and crime combating and prevention. The vision of the SAPS Information and Systems Management (ISM) Strategic Framework is "to enable the optimal use of information by the SAPS in creating a safe and secure environment for all people in South Africa" (SAPS 2002a).

In the Communication Strategy of the government's Justice, Crime and Security (JCPS) Cluster (which includes the SAPS), circulated in June 2002, the objectives include -

- promoting a sense of security and safety in communities by communicating the efforts of the SAPS and government in implementing service delivery; and

- informing and educating the public on the role, progress and campaigns of the SAPS and other departments in the JCPS cluster (JCPS Cluster 2002:7).

The SAPS website, one of the tools utilised to cater for the public's information needs, was established in 1997. It has since grown to be a sizeable online publication. In July 2002 the content of the website was printed and it amounted to almost 2000 A4 pages.

I. Nelly Sonderling completed a Master's degree in information science (cum laude) at the University of Pretoria, Department of Information Science in 2003.

2. Theo Bothma is professor and head of the Department of Information Science, University of Pretoria. 
In line with the concept of "e-Government", which is fast gaining recognition worldwide and in South Africa, it is important for the SAPS, as a government department, also to start looking into how its website could implement the relevant principles and deliver service this way.

e-Government is defined as "the use of information technology, in particular the internet, to deliver public services in a much more convenient, customer oriented, cost effective and altogether different and better way. It affects the Government's dealing with its citizens, business and other public agencies as well as its internal business processes and employees" (Mwanza 2002).

To expand on this definition, Hoekman (2002) explains that e-Government aims at transforming the existing governance systems through digital means by increasing participation, efficiency and effectiveness in order to foster democracy and economic and social development. However, "e-Government is much more about transforming relationships than about technology. There is no smooth transition from 'government' to 'e-Government'" (Di Maio 200I).

\section{Online presence for SAPS}

Investigation into the establishment of the SAPS website in the late 1990s produced few results. No documentation was recorded at the SAPS itself. The SAPS Internet Policy document (SAPS 2000) makes little mention of the SAPS website, although it does reflect indirectly on it. This document which was compiled "to ensure the correct usage of the Internet within the SAPS", states that the Internet "aims to open a window into the SAPS for the public to establish shared trust and to enhance communication by -

- promoting public involvement through sharing the responsibility of crime prevention;

- supplying information;

- supplying crime related information and education; and

- adhering to general requests from the public" (SAPS 2000).

Promoting greater involvement by the private sector in rendering assistance to the SAPS would portend well for the future. If the system of cooperation between the community and the SAPS could be made to work successfully, this could add a further vital contribution towards mobilising all available resources in the battle to prevent and combat the incidence of crime.

The Government Communication and Information Systems (GCIS), which was established in 1998, in 2000 encouraged government departments to establish an online presence in the form of a website (GCIS 2000). The SAPS website, which was already in existence, was thus a forerunner in terms of government online communication.

In 200 I an audit undertaken by GCIS into existing government websites indicated various shortcomings in the SAPS website regarding content, organisation, navigation, design and layout (GCIS 200I). Various factors pointed to the need for the effectiveness of the SAPS website to be assessed; one of the main reasons being that some of the information furnished was not regularly updated. There were a number of concerned and dedicated officials who submitted information for publication from time to time. However, the task was not clearly allocated to specific staff, and various persons at different offices worked at it, when their other tasks permitted.

The task of streamlining and keeping the contents and structure of the SAPS website up to date has been and is complicated by the fact that in terms of legislation, the State Information Technology Agency (SITA) is responsible for establishing and maintaining all government websites. SITA is the IT service agency for the South African government. Its stated aim is to "develop the powerful Internet platform" (Blom \& Willers 200I).

SAPS staff members are responsible for providing the content. SITA then posts it on the website, and updates the design, structure and navigation. This 'remote control' of the website - the SAPS headquarters, where the content is gathered, is situated in the Pretoria CBD, while SITA is on the outskirts of Pretoria - complicates the process, especially regarding the time factor and the proximity of role-players.

Yet there can be no doubt as to the importance of the World Wide Web for the SAPS, or any police agency for that matter, in carrying out its functions and rendering service to its clients today. Commander Dave Pettinari of the Pueblo County Sheriff's department sums it up neatly “... if you come to work without the Internet it will be like a patrolman coming to work without his patrol car. The Internet will be that critical in accomplishing our mission by virtue of more efficient and timely access to information" (in Reynecke \& Fourie 200I:31).

The SAPS website, as all other communication tools, must be assessed in terms of its service delivery, which is required of it as a government communication medium (cf. GCIS 200I). However, if it is to meet the information needs of its online users it must also be an effective website, and, specifically, an effective police agency website.

There is no dearth of literature on the requirements of effective websites in general. However, information as to what makes for an effective police agency website specifically could not be found in secondary sources. 
Given these factors, it was decided to undertake an investigation into possible guidelines for an effective police agency website (cf. Sonderling 2003). In the study undertaken, this was done by examining primary sources - firstly, the needs of users of the SAPS website and, secondly, other police agency websites. From this, guidelines to improve the existing SAPS website could be compiled.

\section{Service delivery}

In this study the SAPS website is regarded as a service delivery tool within the South African government and the SAPS both of which clearly state their roles as service providers.

Much has been written on principles for an effective website. Given the increasing amounts of information being generated in this era (of information), it is not surprising that in a relatively short span of time, the field of website design and content has been well analysed and documented. Author Tom Peters states (Peters 2000:5) that "the world is going through more fundamental change than it has in hundreds, perhaps thousands, of years". He refers to it as "time compression': "Where it took 37 years for the radio to get to 50 million homes, the World Wide Web got there in four". Similarly tutoring in the do's and don'ts of website design and content development has not lagged behind.

In 2000 the SAPS introduced its Service Delivery Improvement Plan (SDIP). The purpose of the SDIP is to provide excellent service to all communities of South Africa. Further, the SDIP focuses upon satisfying customer needs (SAPS s.a.: 78).

The SAPS website, which aims to satisfy customer needs, could thus be regarded as an SDIP tool as well. (Of interest here is that the SAPS is regarded as one of the biggest investors in telecommunications and information technology in Africa. Access to this type of technology is regarded as essential in service delivery and crime fighting (Intelligence 1997:34-38).)

The service that the SAPS website should and could deliver is to inform the community (and SAPS employees) about what is happening within the organisation and what the SAPS is doing, in accordance with its vision, to "create a safe and secure environment for all people of South Africa" (SAPS 2002b: 39).

Further, the government's ideal of "democratic outreach" should be achieved through the SAPS website. Through this ideal the government wants its departments to reach out to communities - in this case via the Internet - and to render service to them. This would, inter alia, entail making online forms available to the public and creating online discussion forums and public opinion polls (GSIC 2000).

The term 'democracy' implies equality and freedom. What does this mean in the context of online government publishing? Landow (1992:78-94) provides answers: "Used in the sense of textuality, it in effect means levelling the playing fields for the reader and the writer, i.e. the writer and the reader become counterparts [...] Anyone using electronic text can ply it to make his own interest the de facto principle. The point of focus depends on the reader [...] This empowers the reader and makes it possible for him to choose his way through text."

In addition, the SAPS website should make it possible for the community to also exchange information with the SAPS; to give opinions on how the SAPS and the SAPS website could better serve them (cf. Bosman in Reynecke \& Fourie 200I:32).

Trowler (in Jones \& Jones 1999:13) refers to such exchange as 'digital liberation'. He substantiates this by saying that consumers acquire more choices. Interaction can take place directly and instantaneously. Democratisation of users increases as information becomes more freely available.

Such 'liberation' in the form of exchange between the service provider and the client is part and parcel of 'interactivity' as it is understood in online or web-based publishing. It includes community involvement in decision-making that focuses on specific priorities and needs of the community (in this case as far as the SAPS website is concerned).

Verwey (1990:103) points out that such feedback and exchange has an effect on interrelationships and consequently on management, and on how the environment (in this case, the website) will be adapted or influenced.

Such community involvement (including the Internet community) in policing is becoming a worldwide trend. In a telephonic interview with Sir John Stevens, the London Metropolitan Police commissioner, in December 200I, he iterated that policing in partnership with the community was becoming increasingly significant in policing in the UK (telephonic interview, 22 December 200I).

In the USA so-called community policing has also been established. Reiner states "Community policing has now become an influential movement among progressive police chiefs in the United States and elsewhere" (Reiner 1992:96).

Goldstein urges police administrators to work with the communities they serve to define the problems that need addressing (Goldstein 1979:246). Bayley (1996) repeatedly expresses the view that in a give-and-take atmosphere, police officials and the public can come to understand each other's perspectives. 
Wadman and Bailey (1993:91) maintain that crime is a community problem and requires community involvement and accountability. Crime prevention is also described as a shared responsibility between law enforcement and the citizen (Ohio Crime Prevention Association 1995:49).

There is therefore a very definite rationale for involving SAPS website users - as a specific community - in the development and maintenance of the SAPS website.

For a police agency website, and, in this case, the SAPS website, to be effective and to deliver service, it must cater for the needs of its users. But as Nielsen (1993: Executive Summary) points out users do not always know what is best for them. Members of the public who visit the SAPS website for various reasons do not necessarily know whether the website has been optimally designed in terms of user-friendliness and whether it does meet their needs as effectively as it could and should. Trenner (in Oppenheim, Citroen \& Griffiths 1990:64) describes user-friendliness as the way a system "handles user errors sympathetically and efficiently, provides support and orientation, accommodates user levels and has a friendly output".

Hugo (in Oosthuizen 1994:34) warns that "Any media centre that ignores its external environment may end up delivering the right products for the wrong needs".

It is therefore the responsibility of the owner of the website to ensure that user needs are attended to.

Despite an extensive search, no relevant literature could be found on specific guidelines for an effective police agency website. One of the aims of the research project, was to do just that, i.e. to determine such guidelines.

Further major requirements in developing and improving a website is the development of a website strategy to show the way forward, an assessment of user needs (which should also be done periodically), and an audit - and subsequent audits from time to time - of the website.

\section{User needs}

To deliver service, user needs must be identified. For the SAPS website to meet the needs of its users it cannot only meet the requirements for a website in general - as a police agency website it has other specific requirements.

Where service delivery underlines the vision and mission of an organisation, the people it serves must be assessed to determine what services they require. Such assessment should not be once off, but should be undertaken periodically.

Misunderstanding regarding user needs is sometimes the result of police making assumptions about what people want. Illustrative of this is where the police in Victoria, Canada held meetings with the community to learn about its concerns. They thought the public would want to discuss the increase in crime. Instead the members of the public complained about noisy parties, vagrants and skateboarders (cf. Jesilow \& Parsons 2000:163).

When the SAPS decided to establish a website in 1997 it requested an outside research company to conduct a survey regarding customer expectations (Ask Africa 1997). This study is discussed in more detail in Sonderling 2003. Although criticism of the survey is recorded, it nonetheless was an attempt to ask the prospective clients or users what they would want published on such a website.

A major recommendation of the survey was that a feedback mechanism be built into the website to facilitate interaction with the SAPS in this way. The current website does have such a mechanism: Website users were furnished with an Internet communication official's e-mail address to direct queries, hints, concerns, etc. This mechanism has enabled the website to stay in touch with its users.

For the purpose of the study, the queries directed to this e-mail address for the period April 200I to May 2002 were analysed. A total of 608 queries were broken down into categories and subcategories to determine what users wanted to see on the website. For details see Sonderling 2003: 33 - 46.

\section{Best practices}

In Sonderling 2003 the best practices of a number of police agency websites are evaluated in detail. In this regard Gurton (1998/99:24) states that when implementing processes and systems, it pays to look at what has succeeded - and failed in the past. This is what constitutes best practices.

An evaluation of online best practices of other police agencies is of substantial value in developing the SAPS website, in terms of both requirements for an effective website in general and also the broad policing purpose, i.e. service delivery. Based on such evaluation a further evaluation framework was subsequently designed to evaluate the SAPS website.

To determine best practices of the websites, the evaluation focused on their content, architecture, technology, style, and service delivery. Service delivery includes the strategy of the website, i.e. whether the website meets its objectives stated implicitly or explicitly - concerning the target audience.

To set about this, the following was done:

- A website evaluation framework was applied to seven police agency websites; and

- A questionnaire was compiled for the police agency webmasters. 
- Publications. Important and updated publications/bulletins/leaflets/posters should be placed on the website and should be downloadable.

- Identification: The website URL should be easy to identify.

- Appeal to a universal audience. Cultural sensitivity should be present.

- Contact details. Users should have access to contact details of the persons/departments in the police service agency they would need to contact.

- Benefits. The benefits that the specific police service offers to the community should be made clear in the content.

- Language and language usage should be clear and error free.

- Mission, vision and strategy of police agency and website. The latter supports the former. Both should be published on the website.

- Logo on home page. This makes it clear how the police agency and website are pursuing its goal of service delivery. It effectively "builds the brand" for the website.

- A dedicated community relationship section. Police agencies worldwide are emphasising the need for partnership policing. It is a requirement today that the community needs to be involved in policing.

- Multicultural diversity section. Communities are becoming increasingly diverse. For a website to render optimal service, this must be taken into consideration. The Lothian and Borders websites, for example, accommodates groups from ethnic minorities by informing them of the official interpreters and language lines that are available.

- Accessibility for disabled persons. This is an e-Government principle in most governments. Police agencies as part of government need to consider the universal accessibility principles.

- Youth focus. Most of the websites have dedicated specific sections to young children and to the youth. In this age of serious concern about juvenile crime, the media have a definite role in the education of children and getting a higher level of involvement in crime awareness and crime fighting.

- Education. A police service agency website should play a strong role in educating people on issues such as drug abuse.

- Research: Ongoing research to develop the website should be conducted.

- Complaints. Users should be informed how to lodge complaints against the police service. This enhances community participation.

- Website feedback. Users should be able to give feedback. This is a valuable way of assessing user needs and opinions.

- Surveys. Surveys on user needs as well as usability studies should be undertaken. This is valuable in gauging user needs and opinions.

\section{1.6 Other aspects}

- Glossary. Given the numerous policing-specific terms, a glossary could be helpful for most users.

- A to Z (alphabetical) index. This could add value.

- Updated information. Furnishing of an update notice that indicates the freshness and currency of the published information. It should clearly identify news or information that has been added in the past two weeks.

- References and author. References and indications of the author(s) make content on the web more credible because it can be verified. Contact details will also be useful.

- Usability testing. Usability testing will point out shortcomings that website developers could then rectify.

- Section on missing/wanted persons. Some websites have such sections, while some do not. This is a contentious issue. Placing details of a wanted person on a website, and not removing it when $s /$ he is no longer being searched for, could result in legal proceedings against the police service.

\section{Development of a websites evaluation instrument}

In order to assess the SAPS website, a websites evaluation instrument was subsequently developed. Its development was based on the findings and recommendations derived from the following:

- The Customer Expectations Measure

- The literature review

- The GCIS audit of government websites

- The SAPS website user needs analysis

- The evaluation of best practices of other police agency websites

The various findings and recommendations elaborated on above were applied to develop the websites evaluation instrument. In addition, sources used to develop the website evaluation framework were also consulted. The website evaluation instrument had seven categories, namely content, architecture (overall design), information architecture (information structure), technology, style, service delivery and delivery of e-Government services.

Mouton (1996:31) explains the purpose of peer evaluation, namely to serve as a control mechanism in the search for truth. "The search for truth is not just another option or a matter of choice. Scientists who are engaged in scientific research are bound, as it were, in a 'moral contract' to commit themselves to the search for truth" (Mouton 1996:31). Mouton (1996:57) refers to "the market of intellectual resources"; such "market" could include peer evaluation as an 
item. Further, he explains (1996:57) that there are two types of resources, theoretical and methodological resources. Methodological resources include all the methods and approaches in the research process. Peer evaluation would be one such approach.

Four persons were approached and appointed as evaluators of the SAPS website. Evaluators were requested to undertake the evaluation of the SAPS website during December 2002 to March 2003, using the websites evaluation instrument. They were the following:

- Evaluator I: A website designer. She was selected because of her experience and ongoing work in the field.

- Evaluator 2: An independent website consultant.

- Evaluator 3: A visitor to the SAPS website (she is a regular visitor) who surfs the World Wide Web daily and has experience in collating information for websites.

- Evaluator 4: A technology designer. He was also selected because of his experience and ongoing work in the field. The rating system the evaluators used was a four-point scale, and evaluators were encouraged to add comments to explain their ratings. Ratings were remarkably consistent, and where there were differences, the comments usually provided sufficient clarification to effectively interpret the differences, The fact that there were some differences is also important, because these differences highlighted each individual evaluator's perceptions of the site.

\section{Recommendations from evaluators' reports}

The four evaluators' assessments of the SAPS website indicated that there was scope for improvement. A summary of the recommendations is given in the table below.

\section{Summary of recommendations from evaluation reports}

\begin{tabular}{l|l}
\hline I. Website content & $\begin{array}{l}\text { - The purpose of the website should be spelt out clearly. } \\
\text { - Attempts could be made to make the home page more engaging. } \\
\text { - More reasons to return should be built into the website content. }\end{array}$ \\
\hline Content & - An "About us" page should be considered. \\
- A "Where to find us" page should be considered. \\
- A Calendar of Events should be established \\
- Updated reports should be posted on the website. \\
- Initiatives should be published regularly. \\
- A "What's new" section should be considered instead of the flashing "New" notices on the home page. \\
\hline - A glossary could add value to the website. \\
- Contact numbers required for content providers. \\
- Contact numbers required for the web team (and not only the webmaster). \\
- Contact details required for authors of articles. \\
- Limit the depth of content to three clicks or less. \\
- Reports could be verified by referring to print copies, where applicable. \\
- Dates of articles should be given. \\
- Updates should be provided. \\
- Terms of use should be clear. \\
- Copyright conditions should be displayed conspicuously. \\
- A privacy statement should be attached.
\end{tabular}

\section{Overall design}

Website structure

Navigation
- Design for an intuitive flow: Positioning of information should be logical - information should be categorised to allow easy movement through the site. The structure should be user-centric.

- More navigation labels should be considered, such as "Site map", "Feedback", "Contact us", and "Help".

- It should be possible to navigate within the website without returning to the home page.

- Give details in more than one language in the search engine.

- A site map would add value to the website.

- The quality of backgrounds used in the website should be investigated.

- The indication of page positions should receive attention: Users need to know where they are on the site.

- Greater use of navigation aids: Where text is long and vertical scrolling is required, navigation aids in the text - such as indicating "Back to top" - could be used.

Links and menus

- All links - external and internal - should be revisited to ensure that they are adequate and that dead links are removed.

- A top menu bar should be implemented and the other menu bars should be examined to determine whether they could be improved. 
3. Website architecture (information structure)

- The structure of information on the entire website should be re-assessed. Child abuse is, for example found under the Kiddie's Corner - where it should not be. Hints on how to act to prevent/counter farm attacks are given on two different pages.

- Following from above, an overall check-up should be undertaken to determine whether information is categorised effectively.

- Menus have a different look and feel. Consistency should be striven for in order to contribute to the website identity.

- Regarding information access, it is not always clear where to find information.

\begin{tabular}{|c|c|}
\hline \multicolumn{2}{|l|}{ 4. Website technology } \\
\hline Features and facilities & $\begin{array}{l}\text { - A search facility should be implemented. } \\
\text { - Downloadable forms should be considered. } \\
\text { - Interactivity is limited to e-mail to the Internet communication official (response@saps.org.za). More } \\
\text { interactivity should be encouraged. } \\
\text { - Browser support could be indicated, i.e. it could be specified on which browser the website is best } \\
\text { viewed. } \\
\text { - Technology is not used innovatively, e.g. no use of multimedia. } \\
\text { - The URL could be reconsidered. } \\
\text { - There is little attention clash on the website. However, the flashing "New" on the home page could be } \\
\text { distracting. This could be looked into. }\end{array}$ \\
\hline World Wide Web factors & $\begin{array}{l}\text { The evaluators are not sure how much website management is undertaken. Such management could be } \\
\text { indicated, by, for example indicating when information is updated and by regularly announcing new } \\
\text { initiatives. }\end{array}$ \\
\hline \multicolumn{2}{|l|}{ 5. Website style } \\
\hline General style & $\begin{array}{l}\text { - The website is described as "functional" rather than attractive. However, to be optimally functional by } \\
\text { attracting users, a website needs to be attractive. } \\
\text { - The visual appeal is lacking and there is no consistent look and feel or identity. } \\
\text { - Visual aspects are not always functional, for example the flashing graphics on the home page are } \\
\text { described as "distracting". The functionality of graphics needs to be examined. } \\
\text { - The information on the website is written in such a way that it is sometimes clumsy. All material should } \\
\text { be edited before it is posted on the website. In addition to impeccable language use, the writing style } \\
\text { should be adapted for web writing. Sentences and paragraphs should be short. Entire documents should } \\
\text { be brief, if possible. }\end{array}$ \\
\hline Specific elements & $\begin{array}{l}\text { - Legibility is not always good. It is sometimes hampered by incorrect use of backgrounds. All text on the } \\
\text { website should be examined for legibility and distracting backgrounds changed or removed. } \\
\text { - Backgrounds and style are widely divergent. Consistency is necessary to establish an identity. } \\
\text { - Usability testing could add value because it could result in features that hamper usability being changed. }\end{array}$ \\
\hline \multicolumn{2}{|l|}{ 6. Website service delivery } \\
\hline Police-specific content & $\begin{array}{l}\text { - The target audiences should be clearly identified and the objectives regarding the audience stated. } \\
\text { - Although the police service strategy has been posted on the web, the one evaluator encountered a } \\
\text { dead link in trying to access it. } \\
\text { - The vision and mission should be placed on the website. } \\
\text { - Policy documents and police service documents do appear on the website. However, there are not } \\
\text { many. More major documents should be accessible. } \\
\text { - Police service successes should be published on the website. } \\
\text { - The statistics on the website that are outdated should be updated. } \\
\text { - Topical issues, for example the Nigerian scam and the spiralling drug abuse, should receive far more } \\
\text { coverage on the website. } \\
\text { - Details of emergency services should be prominently displayed on the website. } \\
\text { - Ways of presenting high-profile crimes need to be addressed. As is stated in the evaluation, it serves no } \\
\text { purpose to relate incidences of hijacking. Users should be told how to avoid this happening and what to } \\
\text { do when it happens. } \\
\text { - More services offered by the police should be promoted on the website. }\end{array}$ \\
\hline
\end{tabular}


- Reporting emergency and non-emergency crime, as well as matters other than crime, is not sufficiently aided on the website. In the case of emergency service, emergency contact numbers are, in some cases, "hidden" somewhere on the website, or buried deep - requiring many clicks, or are confusing. Nonemergency contact numbers are not given. This matter needs to be rectified.

- Reporting crime via e-mail is not encouraged. This is an important service that could be rendered and should be addressed.

- Contact numbers for head office divisions and departments are not given. This should be addressed.

- Contact numbers for police stations are difficult to find (under profiles).

- South Africa has II official languages. Contacting the police in emergency situations and other situations should be facilitated for people belonging to language groups other than English. This aspect needs attention.

\section{Website e-government service delivery}

- Digital democracy needs to be promoted - possibly in the form of discussion forums, online forms and feedback mechanisms.

- The customer service offered via the response@saps.org.za should be promoted. The Internet communication official responds to queries and complaints received via this e-mail address. However, there is no indication on the website how this is managed. Posting such information on the website would let users know that needs are catered for.

- The website should match user sophistication level. Where South Africa has II official languages and many communities from historically disadvantaged backgrounds, these aspects need to be considered in upgrading and developing the website.

Interactive features

- Interactivity should be promoted on the website. This could be done by allowing users to submit content to the website and by enabling more feedback mechanisms and e-mail communication.

- The SAPS journal (a print publication) could be published on the website - giving users more access to SAPS-related information.

- Police initiatives should be published and kept up to date.

- There should be more information on how to deal with emergency situations.

- Vacancies are published, but users are not advised on how to join the SAPS. This should be done.

- User support should be developed.

- Surveys on user needs should be regularly conducted

\section{Implementation of recommendations and possible stumbling blocks}

\subsection{Implementation of recommendations}

The implementation of such recommendations would require streamlined management of the website. In the case of the SAPS website there has been a problem of inadequate staff allocation and consequently lack of planning. In the past the task was not clearly allocated to specific staff, and staff members at different offices would attempt to develop the website when their other tasks permitted.

It is thus clear that the management aspect of the SAPS website must be developed before recommendations could be implemented successfully. Recent discussions with staff at the SAPS department of communication and liaison - which has recently been given the task of overseeing the SAPS website - indicate that this much needed function is now being addressed. Staff has recently been appointed permanently to develop the website.

\subsection{Possible stumbling blocks in implementing recommendations}

Various stumbling blocks exist within the SAPS for implementing these recommendations. They include the following:

- Existing strategies and policies could possibly be inadequate in addressing new kinds of internal and external relationships, and in exploiting new service delivery channels.

- There could be staff members who could strongly oppose change. A reason for this could be that police agencies worldwide are known to be conservative.

- The perception is still fairly common that an online presence is a 'nice to have' but that it is not vital. This is especially true in the South African context. A very small percentage of the South African population has access to computer technology and websites. The question is often asked what portion of the SAPS constituency could actually benefit by online service delivery.

- Bureaucratic processes developed for a hierarchical organisation may prove inadequate in supporting the new constituent-centric approach.

New technologies and architectures must be managed. Budgetary constraints are a daunting factor in this regard. The SAPS is "fighting" a serious war against crime and funds are required and applied first and foremost in the direct crimecombating arena. Its information systems division must state its business case clearly to ensure sufficient investment in technology in the next few years, thereby realising the potential of online services.

An online service delivery strategy needs to address such stumbling blocks. 


\section{Online service delivery strategy}

A vital aspect that goes hand in hand with such development would be the drawing up of an online service delivery strategy and guidelines and a development roadmap for the way forward.

A strategy and guidelines are indispensable in raising the maturity level and quality of the SAPS website. Such a strategy would show what the SAPS would like to achieve with its online service, analyse the current situation, and devise plans for achieving the goals. It would further spell out how the website supports the vision and mission of the organisation.

Management support from executive level is a very high priority in this regard, as considerable resources could possibly be necessary consistently to support the implementation of such strategy. Support from senior management also underlines its dedication to service delivery, which will give the initiative the required momentum to go from planning to development and implementation. In the long run, senior management support is the critical factor that will determine the success of the effort.

In this regard, Unruh (1997:336-337) gives the following three essential conditions for organisations that want to fully use information as resource:

- Senior management that acknowledges the importance of information management to add value to client service.

- An organisation culture that encourages and supports knowledge sharing.

- Acknowledgement of the importance of the best possible technological infrastructure as an empowering factor in value-creation.

Oleson (1997: 3I) cautions that "technology alone is not going to win the race for you". A flexible management team, which can cope with change brought about by development in technology is required.

A development roadmap is equally important. The purpose of such a roadmap is the continued development of the SAPS online services to ensure an effective policing service.

\section{Further research}

At the Regional Workshop on Building e-Governance Capacity in African countries, held in Johannesburg in October/ November 2002, issues such as whether Africa is "e-ready" were discussed. Arguments persist that Africa does not need computers, but water and clothes and other necessities.

The counter-argument made by South African public service and administration minister Geraldine Fraser-Moleketi was that service delivery to all citizens could be improved by making use of technology. She emphasised that slow forms of development in this field had to be leapfrogged (Emdon 2002).

The concept of e-governance is still fairly new to the world at large. It is definitely a form of transparency and democratic behaviour that has not been considered much by police agency websites. This is made clear by the assessments of police agency websites of other countries in this study.

The adoption of e-governance by police agencies therefore requires in-depth research. This is especially true for police agencies in Africa, where the digital divide is an undeniable reality. e-Government is primarily about access creating access to services for citizens through the means convenient to them.

The SAPS could benefit by further research into how e-Governance could impact positively on police service delivery. The following research areas are indicated:

- A strategy and guidelines for improving the quality of the SAPS website, supported by a roadmap that provides more detail on the steps required in the development of online services.

- Measuring the impact that electronic media could have on the South African citizen's life as far as safety and security are concerned. This may include increased awareness of high-crime areas, scams, incidence of vehicle thefts, etc.

- Mechanisms the SAPS should apply for bridging the digital divide, in order to deliver its services online to the large part of its constituency that does not have access to information and communication technologies.

- Ways that South Africa, as a leader in the use of telecommunications on the African continent, could assist other African countries in combating crime and ensuring a peaceful and fair society, through the use of online service delivery methods.

- The use of automated mechanisms to ensure updated content on a website such as that of the size of the SAPS. This should be supported by clear policy that states the responsibility for content.

- The role of NEPAD and its role-players in drawing up an African development plan for information and communication technologies - and, specifically, the SAPS participation in this regard.

- The role of electronic government and information systems in supporting the fight against crime.

- The role of the electronic media in improving the image of SAPS with the constituency - including ways in which this media could support the government's commitment to transparency and good governance.

- Ways that the SAPS electronic media could be used in supporting the SAPS training and development goals, such as by creating an internal awareness of the SAPS national strategy, and of its special programmes and objectives.

- The development of a measurement tool for quantifying the impact of online services on the SAPS in reaching the 
eight objectives of the South African government's Batho Pele ("People first”) initiative.

\section{Conclusion}

In this study, based on Sonderling 2003, it was found that a framework for measuring an effective police agency website was not readily available. This was confirmed in discussions with several police agencies elsewhere in the world.

A study was conducted to determine current best practices in some of the English-speaking countries. A measuring instrument was designed that reflected current best practices. Knowledgeable evaluators measured the current website and provided feedback on its features.

This resulted in a clear definition of the weaknesses of the current website, with pointed recommendations for enhancing online service delivery and e-governance by using a solid online service delivery strategy and a development roadmap.

The evaluation of the SAPS website proved the effectiveness of the website evaluation framework. Adherence to the specific issues addressed in the framework will ensure that the SAPS website communicates effectively to its target market, the South African public. This will further ensure that electronic media are used optimally in supporting the SAPS national strategy.

\section{References}

Ask Africa. 1997. Customer Expectations Measure. Pretoria: Ask Africa.

Bayley, D.H. 1996. What works in policing. New York: Oxford University Press.

Blom, A. \& Willers, J.C. 200I. SITA Internet and Intranet web site policy. Document No. SQSD-00050. Pretoria: SITA.

Department of Public Service and Administration. 2002. Batho Pele. [Online]. Available: http://www.dpsa.gov.za/projects/bathopele/faqs.htm\#ql.

Di Maio, Andrea. 200I.The European E-government Scenario, Gartner Group European Spring Symposium, 28-30 March 200I, Florence, Italy.

Emdon, Clive. 2002. E-governance can advance aims of Nepad. Business Day. 8 November.

GCIS. 2000. Presentation to the Parliamentary Portfolio Committee on Communications on 7 March 2000. GCIS: Pretoria.

GCIS. 200I. Audit of government web sites February/March 200I. GCIS: Pretoria.

Goldstein, H. 1979. Improving policing: A problem-oriented approach. Crime and delinquency, 25, pp. 236-258.

Gurton, Annie. 1998/99. Best practices. Police, Justice \& Identification (98/99:24-27).

Hoekman, Arie. 2002. e-Governance and the promotion of transparency in governance. Regional workshop on building egovernance in Africa. October 28-3I. Johannesburg.

Intelligence. 1997. Technology fights crime: IT warfare. July: 34-8.

ISS. 200I. A critical distance: Public perceptions and police service. [Online]. Available: http://www.iss.co.za/PUBS/CRIMEINDEX/ OIVOL5NO3/critical.html.

JCPS Cluster. 2002. Communication strategy. Pretoria.

Jesilow, Paul \& Parsons, Deborah. 2000. Community policing as peacemaking. Policing and society. 10(2): 163.

Jones, Marsha \& Jones, Emma. 1999. Mass media. London: MacMillan.

Landow, G.P. 1992. Hypertext - The convergence of contemporary critical theory and technology. Baltimore: The John Hopkins University Press. London: Bowker-Saur.

Morris, Lynn Lyons, Fitz-Gibbon, Carol Taylor and Freeman, Marie, E. 1987. How to communicate evaluation findings. London: Sage.

Mouton, Johann. 1996. Understanding social research. Pretoria: Van Schaik.

Mwanza, Joel, J. 2002. Integrated financial management system - the Tanzanian case. Regional workshop on building e-governance in Africa. October 28-31. Johannesburg.

Nielsen, Jacob. 1993. Usability engineering. Boston: AP Professional.

North, C.A. 1998. 'n Verkennende ondersoek na die aard en funksies van 'n uitgewershuis vir die Universiteit van Pretoria. Unpublished MA dissertation. Pretoria: University of Pretoria.

Ohio Crime Prevention Association. 1995. The guidebook to community policing in Ohio. Ohio: Crime Prevention Association.

Oleson, D.E. I 997. Making technology matter. Vital speeches of the day. LXIII(II), March I5: 313-316.

Oosthuizen, S.J.P. 1994. The role of audiovisual service units within organisations. Stellenbosch University: Stellenbosch.

Oppenheim, Charles, Citroen, Charles L, \& Griffiths, José. 1990. Perspective in information management. 2. London: BowkerSaur.

Peters, Tom. 2000. Time. 29 May 2000:5.

Police agency Australian Federal Police. [Online]. Available: $h t t p: / / w w w . a f p . g o v . a u$.

Police agency website Essex (England). [Online]. Available: $h t t p: / / w w w . e s s e x . p o l i c e . u k$.

Police agency website Hong Kong. [Online]. Available: $h t t p: / / w w w . i n f o . g o v . h k / p o l i c e$.

Police agency website London Metropolitan (England). [Online]. Available: $h t t p: / / w w w . m e t . p o l i c e . u k$.

Police agency website Lothian and Borders (headquarters in Edinburgh, Scotland). [Online]. Available: http:// www.lbp.pnn.police.uk.

Police agency website Princeton borough, New Jersey, USA. [Online]. Available: .

Police agency website Strathclyde (headquarters in Glasgow, Scotland). [Online]. Available: http://www.strathclyde.pnn.police.uk.

Reiner, Robert. 1992. The politics of the police. (2 ${ }^{\text {nd }}$ ed.) New York: Harvester Wheatsheaf.

Reynecke, Frik \& Fourie, Marius. 200I. Police management beyond 2000. Landsdowne: Juta.

SA Jnl Libs \& Info Sci 2005, 7 I (I) 
SAPS. 2000. SAPS Internet Policy document. Pretoria: SAPS Head Office.

SAPS. 2002a. Strategic Plan for the South African Police Service. Pretoria: SAPS Head Office.

SAPS. 2002b. 2001/2002 Annual Report. [Online]. Available: http://www.saps.org.za.

SAPS. s.a. Transforming of the SAPS through Service Delivery Improvement. Pretoria: SAPS Head Office.

Sonderling, Nelly E. 2003. Scoping and developing the SAPS website for online service delivery. Unpublished Masters of Information Science dissertation. Pretoria: University of Pretoria.

Stevens, Sir John.200I. Telephonic Interview on 22 December. Pretoria. South Africa.

Unruh, J.A. 1997. Mining the gold in your organization. Vital speeches of the day. LXIII(I I), March I5: 336-339.

Verwey, S. 1990. Die rol van kommunikasieklimaat in persepsies van organisasieklimaat van die formele organisasie. Johannesburg: Rand Afrikaans University.

Wadman, Rovert C. \& Bailey, Sir Stanley, E. 1993. Crime and community policing. Chicago: University of Illinois. 